\title{
Status of Sample Return Propulsion Technology Development under NASA's ISPT Program
}

\author{
David J. Anderson \\ NASA Glenn Research Center \\ 21000 Brookpark Road \\ Cleveland, OH 44135 \\ 216-433-8709 \\ David.J.Anderson@nasa.gov \\ Louis Glaab \\ NASA Langley Research Center \\ 1 North Dryden Street \\ Hampton, VA 23681 \\ 757-864-1159 \\ Louis.J.Glaab@nasa.gov
}

\author{
Michelle M. Munk \\ NASA Langley Research Center \\ 1 North Dryden Street \\ Hampton, VA 23681 \\ 757-864-2314 \\ Michelle.M.Munk@nasa.gov \\ Eric Pencil \\ NASA Glenn Research Center \\ 21000 Brookpark Road \\ Cleveland, OH 44135 \\ 216-977-7433 \\ Eric.J.Pencil@nasa.gov
}

\author{
John Dankanich \\ Gray Research, Inc. \\ 21000 Brookpark Road \\ Cleveland, OH 44135 \\ 216-433-5356 \\ John.Dankanich@nasa.gov \\ Todd Peterson \\ NASA Glenn Research Center \\ 21000 Brookpark Road \\ Cleveland, OH 44135 \\ 216-433-5350 \\ Todd.T.Peterson@nasa.gov
}

\begin{abstract}
The In-Space Propulsion Technology (ISPT) program was tasked in 2009 to start development of propulsion technologies that would enable future sample return missions. ISPT's sample return technology development areas are diverse. Sample Return Propulsion (SRP) addresses electric propulsion for sample return and low cost Discovery-class missions, propulsion systems for Earth Return Vehicles (ERV) including transfer stages to the destination, and low technology readiness level (TRL) advanced propulsion technologies. The SRP effort continues work on HIVHAC thruster development to transition into developing a Hall-effect propulsion system for sample return (ERV and transfer stages) and low-cost missions. Previous work on the lightweight propellant-tanks continues for sample return with direct applicability to a Mars Sample Return (MSR) mission with general applicability to all future planetary spacecraft. The Earth Entry Vehicle (EEV) work focuses on building a fundamental base of multi-mission technologies for Earth Entry Vehicles (MMEEV). The main focus of the Planetary Ascent Vehicles (PAV) area is technology development for the Mars Ascent Vehicle (MAV), which builds upon and leverages the past MAV analysis and technology developments from the Mars Technology Program (MTP) and previous MSR studies.
\end{abstract}

\section{TABLE OF CONTENTS}

1. INTRODUCTION

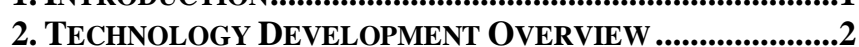

3. ELECTRIC PROPULSION FOR SAMPLE RETURN AND DISCOVERY-CLASS MISSIONS

4. Planetary Ascent Vehicle (PAV) ............................4

5. PRopulsion CoMPONENT TECHNOLOGIES ....................5

6. MULTI-MISSION EARTH ENTRY VEHICLE (MMEEV)...6

7. SYSTEMS/MISSION ANALYSIS .. .7

8. CoNCLUSION AND FUTURE PLANS.....................................8

ACKNOWLEDGMENTS .....................................................8

REFERENCES ................................................................99

U.S. Government work not protected by U.S. copyright
BIOGRAPHIES 10

\section{INTRODUCTION}

NASA's Science Mission Directorate (SMD) missions seek to answer important science questions about our planet, the Solar System and beyond. To meet NASA's future science mission needs, the goal of the ISPT Program is the development of new enabling propulsion technologies that cannot be reasonably achieved within the cost or schedule constraints of mission development timelines. Since 2001, the In-Space Propulsion Technology (ISPT) Program has been developing in-space propulsion technologies that will enable and/or benefit near and mid-term NASA robotic science missions by significantly reducing cost, mass, and/or travel times. ISPT technologies will help deliver spacecraft to SMD's destinations of interest. In 2009, the ISPT program was tasked to start development of propulsion technologies that would enable future sample return missions.

An objective of ISPT is to develop capabilities that realize near-term and mid-term benefits. The Program primarily focuses on technologies in the mid TRL range (TRL 3 to 6+ range) that have a reasonable chance of reaching maturity in 4-6 years. The objective is to achieve TRL 6 and reduce risk sufficiently for mission infusion. The program strongly emphasizes developing propulsion products for NASA flight missions that will ultimately be manufactured by industry and made equally available to all potential users for missions and proposals.

The ISPT priorities and products are tied closely to the science roadmaps, the SMD's science plan, and the decadal surveys. ISPT emphasizes technology development with mission pull. Initially, ISPT's responsibility was to develop technologies for Planetary Science Flagship missions (large, typically > \$1B), but in 2006 the focus evolved to technology investments that would also be applicable to New Frontiers (medium-class, typically \$500M- \$1B)) and 
Discovery (small-class, typically, $<\$ 500 M$ ) competed missions.

Looking towards ISPT's future, the 2011 Planetary Science Decadal Survey[1] was released March 2011, and will provide guidance for ISPT's future technology investments. The Decadal Survey made many references to ISPT technologies such as aerocapture, NEXT, AMBR, and astrodynamics, mission trajectory and planning tools. This Decadal Survey validated the technology investments ISPT has made over the last 10 years, and provides ISPT with a new focus for the next 10 to 20 years.

The Decadal Survey members supported NASA developing a multi-mission technology investment program that will "preserve its focus on fundamental system capabilities rather than solely on individual technology tasks." The Decadal Survey highlighted the NEXT system development as an example of this "integrated approach" of "advancement of solar electric propulsion systems to enable wide variety of new missions throughout the solar system." The Survey committee also recommended "making similar equivalent systems investments" in the advanced Ultraflex solar array technology and aerocapture. The Decadal Survey discussed the importance of developing those system technologies to TRL 6.

One recommendation in the Decadal Survey was for "a balanced mix of Discovery, New Frontiers, and Flagship missions, enabling both a steady stream of new discoveries and the capability to address larger challenges like sample return missions and outer planet exploration.” These broad mission needs would in turn require a balanced set of multimission technologies and integrated system capabilities. The Decadal Survey acknowledges that a "robust Discovery and New Frontiers Program would be substantially enhanced by such a commitment to multi-mission technologies." The Survey identified the highest priority Flagship mission as the Mars Sample Return (MSR) campaign.

This paper provides a brief overview of the ISPT program. It describes the planning and development status of InSpace propulsion technologies in the areas of electric propulsion for Earth Return Vehicles (ERV) and Discoveryclass small-body sample return missions. Planetary ascent vehicles (PAV), Earth Entry Vehicles (EEV), other advanced propulsion technologies, and mission/systems analysis are included. These In-Space Propulsion technologies are potentially enabling for future NASA flagship and sample return missions currently under consideration. They have broad applicability to future Discovery and New Frontiers mission solicitations. For more background on ISPT, please see References [2,3,4,5].

\section{TECHNOLOGY DEVELOPMENT OVERVIEW}

ISPT emphasizes technology development with mission pull. In the near-term, the ISPT goal is to develop propulsion technologies for sample return and Discoveryclass missions. Sample return missions could be quite varied. Samples could be collected and returned to earth of soil and rocks from comets or asteroids, or atmosphere from planets or moons. The current technology development areas for ISPT are: 1) Sample Return Propulsion (SRP), 2) Planetary Ascent Vehicles (PAV), 3) Entry Vehicle Technology (EVT) focus area, and 4) Systems/mission analysis and tools that focuses on sample return propulsion.

The SRP area is divided into: 1) Electric propulsion for sample return and low cost Discovery-class missions, 2) Propulsion systems for Earth Return Vehicles (ERV) including transfer stages to the destination, and 3) Propulsion system components and low TRL advanced propulsion technologies. The SRP effort will complete the development to TRL 6 of the NEXT ion engine system and will continue work on HIVHAC thruster development in FY2012. The HIVHAC thruster then transitions into development of a HIVHAC system under future Electric Propulsion for sample return (ERV and transfer stages) and low-cost missions. Previous work on the lightweight propellant-tanks continues under advanced propulsion technologies for sample return with direct applicability to a Mars Sample Return (MSR) mission and with general applicability to all future planetary spacecraft.

The current focus of the Planetary Ascent Vehicles (PAV) area is the technology development for a Mars Ascent Vehicle (MAV). The Planetary Ascent Vehicles (PAV)/Mars Ascent Vehicle (MAV) is a new development area for ISPT. It builds upon and leverages the past MAV analysis and technology developments from the Mars Technology Program (MTP) and previous MSR studies. The MAV is a key component of any future MSR mission.

The Entry Vehicle Technology (EVT) area is divided into three main areas: 1) Aerocapture, 2) Multi-mission technologies for Earth Entry Vehicles (MMEEV), and 3) Planetary probes and impactors. ISPT's earlier Aerocapture efforts conclude in 2011, and ISPT is working to find opportunities to transition the technology into future flight opportunities. The Aerocapture experience base and capability will be leveraged with previous work related to Earth Entry Vehicles (EEV) and transitioned into the future multi-mission technologies for Earth Entry Vehicles (MMEEV).

The systems analysis technology area performs numerous mission and system studies to guide technology investments and quantify the return on investment. Recent focus of the systems analysis area is on developing reference missions and conducting mission sensitivities to assist technology gap identification or application.

\section{Electric Propulsion for SAMPle ReturN AND DISCOVERY-CLASS MISSIONS}

ISPT is investing in Sample Return Propulsion technologies for applications for Earth-Return Vehicles for large and small bodies. The first example leverages the development of a High-Voltage Hall Accelerator (HIVHAC) thruster into 
a lower-cost electric propulsion system.[2,6] HIVHAC is the first NASA electric propulsion thruster specifically designed as a low-cost electric propulsion option. It targets Discovery and New Frontiers missions and smaller mission classes. The HIVHAC thruster does not provide as high a maximum specific impulse as NEXT, but the higher thrustto-power and lower power requirements are suited for the demands of some Discovery-class missions and sample return applications.

Advancements in the HIVHAC thruster include a large throttle range from $0.3-3.5 \mathrm{~kW}$ allowing for a low power operation. It results in the potential for smaller solar arrays at cost savings, and a long-life capability to allow for greater total impulse with fewer thrusters. The benefits include cost savings with a reduced part count and less-complex lowercost propulsion system.



Figure 1 - HIVHAC thruster Engineering Model

Wear tests of the NASA-103M.XL thruster validated and demonstrated a means to mitigate discharge channel erosion as a life-limiting mechanism in Hall thrusters. The thruster, shown in Figure 1, operated in excess of 5500 hours (115 kg of xenon throughput) at a higher specific impulse (thruster operating voltage) as compared to SOA Hall thrusters.

Components for two Engineering Model (EM) thrusters were designed and fabricated. Preliminary performance mapping of the EM thruster at various operating conditions was performed at NASA Glenn Research Center (GRC).[2,6] The EM thruster hardware was operated in vacuum test environments for operations and performance assessments. The results indicated that several design changes were needed to resolve problems with thermal design, boron-nitride advancement mechanisms, magnetic topology, and high-voltage isolation. A list of rework items was compiled and design corrections were identified and evaluated by either analysis and/or test. The design improvements were implemented in a reworked engineering model design, which is designated as EM-R. Vacuum Facility 12 (VF-12) will be used to conduct the official performance acceptance test (PAT), given the pumping speed and resulting vacuum chamber background pressure. However, leaks in the liquid nitrogen panel have hampered facility availability for testing. As a result EM-R operation and performance tests were conducted in a smaller vacuum facility to demonstrate effectiveness of hardware design changes. The results indicate that performance and operational requirements should be met with EM-R hardware. In the future, the test sequence will include performance acceptance tests, environmental tests and a long duration wear test in FY12. Current plans include the design, fabrication and assembly of a full Hall propulsion system. These are pending final approval to proceed.

In addition to the thruster development, the HIVHAC project is evaluating power processing unit (PPU) and xenon feed system (XFS) development options. These were developed under other efforts, but can apply directly to a HIVHAC system. The goal is to advance the TRL level of a Hall propulsion system to level 6 in preparation for a first flight.

The functional requirements of a HIVHAC PPU are operation over a power throttling range of 300 to $3,800 \mathrm{~W}$, over a range of output voltages between 200 and $700 \mathrm{~V}$, and output currents between 1.4 and $5 \mathrm{~A}$ as the input varies over a range of 80 to $160 \mathrm{~V}$. A performance map across these demanding conditions was generated for one candidate option[2,6] that is being developed through NASA Small Business Innovation Research (SBIR) Program. Beyond conventional feed system options, one option for feed systems that was demonstrated with the Hall thruster is the advanced xenon feed system developed by VACCO.

To continue to simplify and reduce the cost of the HIVHAC system, the ISPT program invested in its reliable, lightweight, and low-cost xenon flow control system.[7] A follow-on contract was awarded to VACCO as a joint ISPT and Air Force effort to qualify a Hall system flow control module. This module would significantly reduce the cost, mass, and volume of a Hall thruster xenon control system while maintaining high reliability and decreasing tank residuals. This is the first time the ISPT program advanced a component technology to TRL 8 to further reduce the risk and cost of the first user. The new Hall module, shown in Figure 2, is scheduled to complete its qualification program in March 2012. The module is then planned for inclusion in a HIVHAC thruster long duration wear test along with the SBIR PPU as an integrated string test of the HIVHAC system. A second flow control module unit (an acceptance tested flight unit) has been ordered and should be delivered in December 2012. 


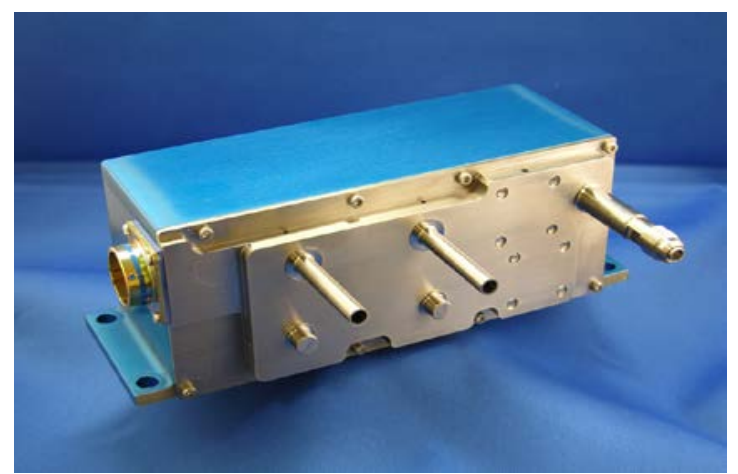

Figure 2 - Hall thruster xenon flow control module.

The Near-Earth Object (NEO) mission was evaluated, and the HIVHAC thruster system delivered over 30 percent more mass than the NSTAR system. The performance increase accompanied a cost savings of approximately 25 percent over the SOA NSTAR system. The Dawn mission was evaluated, and the expected HIVHAC Hall thruster delivered approximately 14 percent more mass at substantially lower cost than SOA, or decreasing the solar array provided equivalent performance at even greater mission cost savings.[2, 6]

The second technology example of a Sample Return Propulsion Technology is the BPT-4000 Hall thruster development. ISPT has invested in a life-test extension of the thruster to improve total impulse demonstrated capabilities. Under evaluation is the operation of this thruster design at higher operating voltages, which improve thruster specific impulse. There are mission studies that indicate that BPT-4000 is directly applicable to ERV and Discovery-class missions. For more HIVHAC information, see References [8,9].

\section{Planetary Ascent Vehicle (PAV)}

For many years, NASA and the science community asked for a Mars Sample Return (MSR) mission. There were numerous studies to evaluate MSR mission architectures, technology needs and development plans, and top-level requirements. Because of the challenges, technologically and financially of the MSR mission, NASA initiated a study to look at MSR propulsion technologies through the ISPT Program Office. The objective of the ISPT Program is to develop propulsion technologies that enhance or enable NASA science missions for the Planetary Science Division (PSD) by increasing performance while reducing cost, risk, and/or trip length. The largest propulsion risk element of the MSR mission is the Mars Ascent Vehicle (MAV).

The current architecture (Figure 3) for the MSR lander is to use the Mars Science Laboratory (MSL) entry, descent, and landing (EDL) system.[10] Using the MSL sky crane concept places significant environmental, physical envelope and mass limitations on the MAV system options.

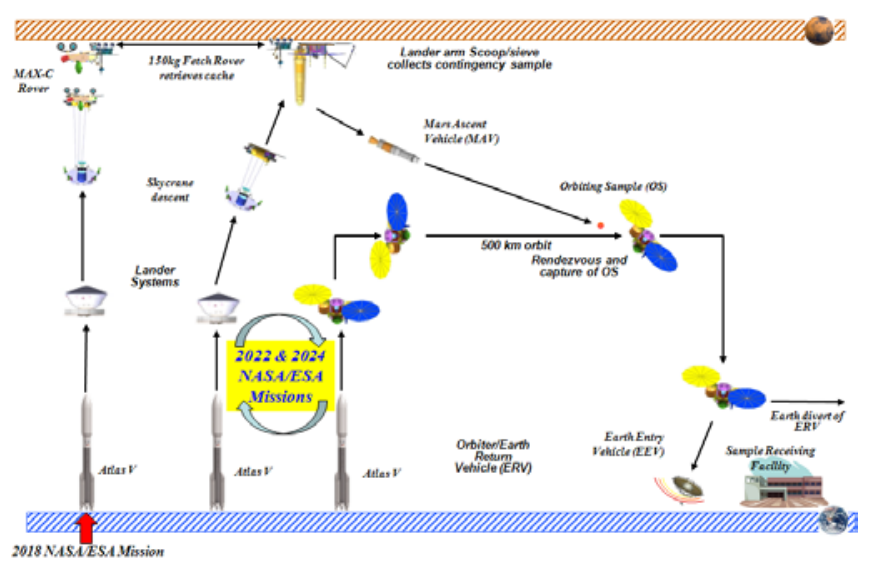

Figure 3 - MSR baseline architecture

Beyond the limitations of the EDL system, the MAV (Figure 4) has specific requirements to deliver the orbiting sample (OS) into an orbit suitable for the Earth Return Vehicle (ERV). Many of the subsystem requirements of the MAV are still to be determined, with many to be defined by the prime integrator during development. However, the driving top-level requirements of the MAV include:

1) The MAV shall deliver a $5 \mathrm{~kg}, 16 \mathrm{~cm}$ sphere (Sample Container), to a low Mars orbit.

2) The Mars orbit must achieve a periapsis greater than $460 \mathrm{~km}$ and an apoapsis less than $580 \mathrm{~km}$ with an inclination of $45^{\circ}+/-0.2^{\circ}$.

3) The MAV shall transmit both real-time and recorded engineering data to an orbiting asset with sufficient fidelity to discern root cause of failure or off-nominal performance.

4) The MAV must not require sub-centimeter centerof-gravity accuracy.

5) The MAV shall fit within the physical constraints of the Mars Science Laboratory (MSL) Entry Decent and Landing (EDL) system.

6) The MAV shall be single fault tolerance where appropriate.

Another challenge for the MAV is to meet the environmental requirements for the mission. The environmental requirements include the Earth launch, transit within the cruise stage, the Mars EDL, and finally a long surface stay on Mars. The environments anticipated to influence the system design are the vacuum environment during cruise, the $15 \mathrm{~g}$ quasi-static lateral load during EDL, and the diurnal temperature cycling, as low as $-99^{\circ} \mathrm{C}$ during the surface stay. The thermal requirements necessitate a thermal enclosure or "igloo" in order to maintain practical lander power requirements. A detailed set of requirements and system design standards and guidelines has been established for all study participants to ensure comparable system capability and margins.[11]

Through the NASA Research Announcement (NRA) process, the ISPT program solicited MAV system designs 
and plans to initiate propulsion system development. Multiple contractors were selected to proceed in October of 2010 and efforts were initiated in February 2011. Awards were made to ATK, Lockheed Martin, and Northrop Grumman to develop MAV concepts using solid-solid, solid-liquid, and liquid-liquid $1^{\text {st }}$ and $2^{\text {nd }}$ stage propulsion systems respectively. During the NRA efforts, the contractors completed Principal Investigator (PI) led collaborative engineering designs of the MAV and will begin contract options to develop the required technologies in early FY12. Additionally, Firestar Technologies is working, under an SBIR, to develop a Nitrous Oxide Fuel Blend propulsion system applicable to the MAV.[12] The results of the industry efforts indicate that while technology development remains, there are multiple paths to meet performance and requirements of the Mars Ascent Vehicle. The industry efforts and designs are documented in the IEEE literature.[13,14,15,16].

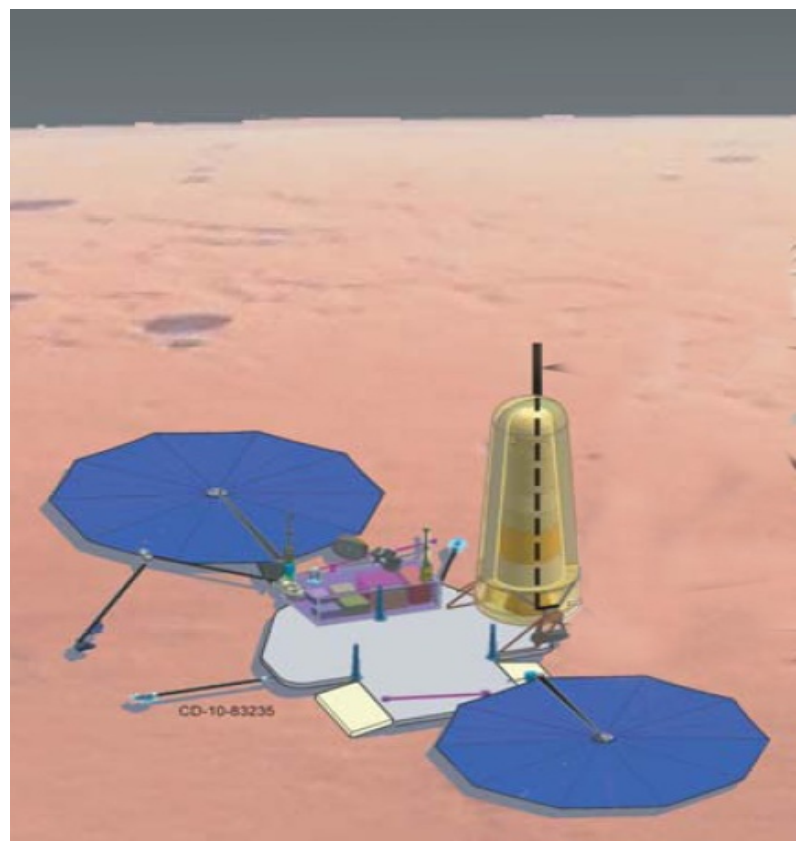

Figure 4 - MAV Launch Platform

NASA performed system design studies with the Jet Propulsion Laboratory's (JPL) Team-X and GRC's COMPASS teams.[13] The collaborative designs included a system level optimization using the industry designs and an internal "leveled" design to allow comparison of system mass, complexity, and maturity. The trades included the MAV support systems and lander impacts to minimize the total landed mass. The preliminary results of the studies indicate that the baseline solid-solid system appears to offer the lowest mass solution, but it may have challenges achieving the required orbit dispersion accuracies The solidliquid option has a slightly higher mass, imposing more thermal requirements on the lander, but can reduce dispersion errors. The liquid-liquid option has the highest mass growth potential due to its mass fraction relative to a solid motor, but requires the least lander resources and has very tight dispersions. The preliminary NOFBx system evaluation indicates it may be a competitive option, but is unlikely to offer a single stage to orbit solution with a lower mass than the two-stage solid. The baseline MAV concept design is shown in Figure 5. The baseline design is predecisional and for understanding design trades and sensitivities. It does not represent any concept selection.

Each of the MAV concepts was evaluated for risk and technology maturation and was recommended, primarily in the propulsion elements. The ongoing NRA work will initially focus on the key risks of the individual propulsion systems at the component level. All of the MAV concepts are moving forward at various levels. The MAV project team expects to achieve a milestone in late FY12 to address the key risks of each option and determine the final viability of various concepts. If the concepts are viable with respect to mass, volume, and risks, an integrated propulsion stage demonstration is planned to conclude in FY14. If sufficient risk can be reduced through the NRA, NASA may solicit an engineering model MAV development with an objective of a vehicle terrestrial flight demonstration. In order to meet the planned Mars Sample Return lander launch date in 2024, it is necessary to complete the first EM MAV demonstration in 2018.

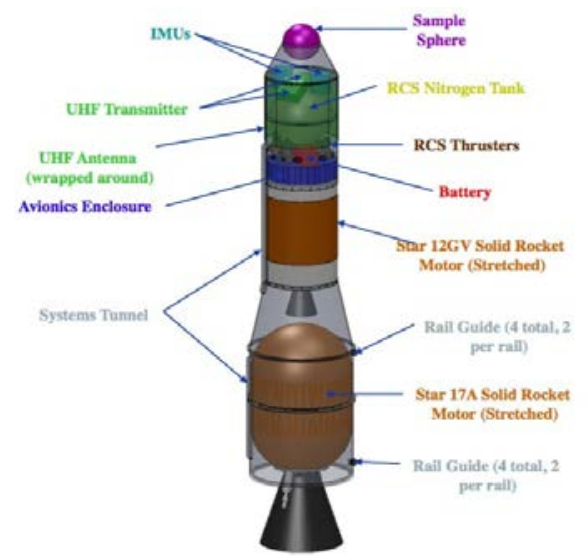

Figure 5 - Baseline MAV Concept Design

\section{Propulsion Component Technologies}

ISPT invests in the evolution of component technologies that offer significant performance improvements without increasing system level risk. Two component technologies currently receiving investments are xenon feed systems (discussed in the previous section) and Ultra-Light Tank Technology (ULTT).

The ISPT Program invested in ultra-lightweight tank technology (ULTT) led by JPL. The ULTT efforts in the past focused on manufacturability and non-destructive evaluation of the lightweight tanks. The tank effort continues to validate defect-detection techniques to maintain NASA standard compliance for ultra-thin wall tanks. The follow-on potential is to develop and qualify positive expulsive ultra-lightweight tanks specifically for the MSL 
SkyCrane. The SkyCrane tanks offer mass savings on the order of $24 \mathrm{~kg}$. This is dependent on the final tank wall thickness. The mass reduction would increase the landed mass capability of SkyCrane for a relatively low cost per kg. The SkyCrane Entry Descent Lander (EDL) system is planned for the 2018 NASA/European Space Agency Mars mission and for the Mars Sample Return (MSR) mission. Both are highly mass constrained. The Mars Science Laboratory (MSL) SkyCrane, with large propellant tanks, is shown in Figure 6. While this particular tank design will be qualified for the SkyCrane application (Figure 7), the ultralightweight technology will be applicable for a wide range of future science missions. Propulsion tanks remain the highest dry-mass reduction potential within chemical propulsion systems. This technology would significantly push the state-of-the-art with the promise of a $2 \mathrm{X}$ improvement over conventional tank designs.

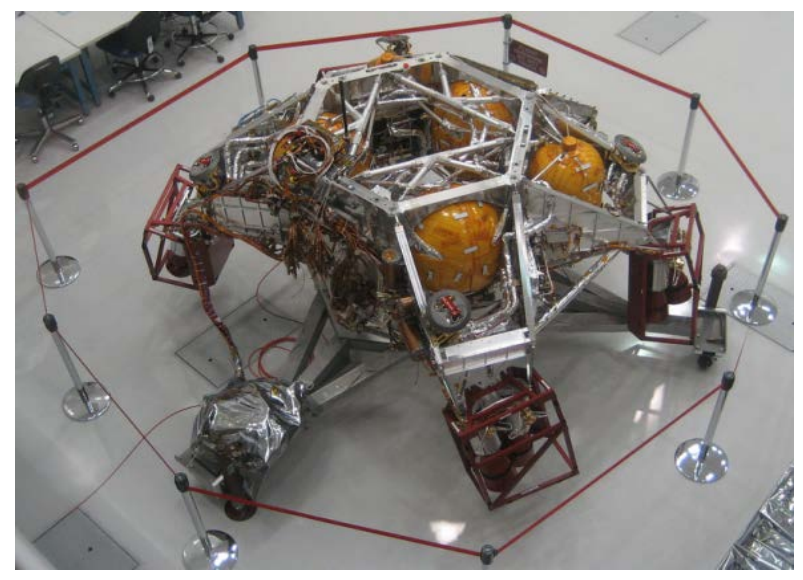

Figure 6 - MSL SkyCrane
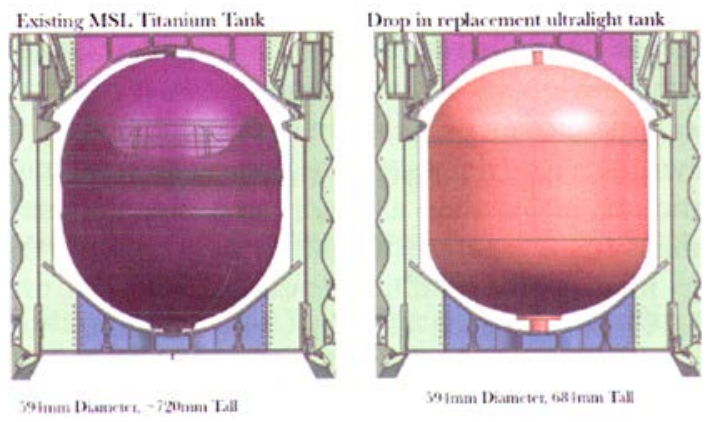

Figure 7 - Ultra-Light Weight tank on left.

The development effort is divided into two main tasks: a Non-Destructive Inspection (NDI) task and the ultralightweight tank design/manufacturing/testing task. The NDI task completed an initial assessment of several NDI techniques, such as eddy-current and surface wave ultrasonic techniques. The results from the tests indicate that these techniques are adequate to find cracks as small as 0.003 inches in the titanium lining. The objective for the NDI task is to establish the crack size that can be detected consistently using these new methods. The ultra-lightweight tank development task would incorporate the NDI technique in the manufacturing and qualification of the new tank. In order for the tank design to be a success, the approach must demonstrate "safe life." Safe life for non-toxic materials requires proving a design will leak-before-burst. Safe life for toxic liquids, like hydrazine, is more stringent. The NDI technique must be able to detect small cracks in the thin liners, then the NDI results need to be verified, by test, that worst-case crack growth will not grow to failure. Evaluation of the NDI techniques were completed and manufacturing of the NDI samples is underway. In parallel the ultralightweight development work will be completed through a contracted effort with ATK, the suppliers of the MSL tanks. The work will be divided into several phases: design, manufacturing and acceptance/qualification tests. The test phase will include cyclic testing of the flawed liner tank design to demonstrate leak-before-burst and safe life requirements.

The design phase is initiated with the Preliminary Design Review (PDR) to be held in January 2012. The development effort will need to be completed by August 2013 in order to maintain a six-month schedule margin for the spacecraft PDR for Mars 2018, which is anticipated in February of 2014.

\section{MULTI-MisSiON EARTH ENTRY VEHICLE (MMEEV)}

The Multi-Mission Earth Entry Vehicle (MMEEV) is a flexible design concept. It can be optimized or tailored by any sample return mission, including lunar, asteroid, comet, and planetary (e.g. Mars), to meet that mission's specific requirements. The Mars Sample Return (MSR) Earth Entry Vehicle (EEV) design, due to planetary protection requirements, is designed to be the most reliable space vehicle ever flown. It provides an effective foundation for many sample return missions. By leveraging common design elements, this approach can significantly reduce the risk and associated cost in development across all sample return missions. It provides significant feed-forward risk reduction in the form of technology development, testing, and even flight experience.

The current MMEEV parametric configuration is presented in Figure 8 (basic vehicle architecture), and Table 1 (parametric variables). Because each individual sample return mission may have a unique set of performance metrics of highest interest, the goal is to provide a qualitative performance comparison across a specified trade space. Each sample return mission can then select the most desirable design point to begin a more optimized design. 


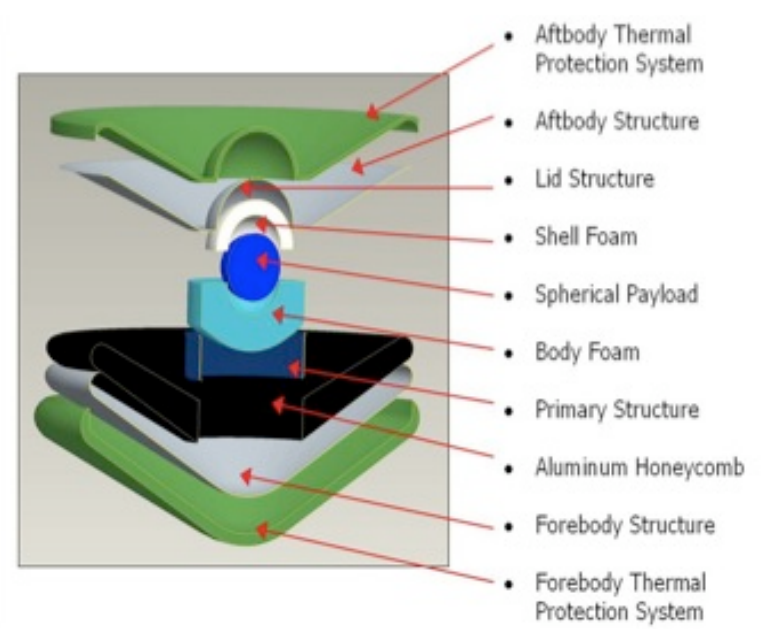

Figure 8 - Basic MMEEV architecture

Table 1. MMEEV parametric variable

\begin{tabular}{|l|l|}
\hline Parametric Variable & Range \\
\hline Payload & 5 to $30 \mathrm{~kg}$ \\
\hline Vehicle Diameter & 0.5 to $2.5 \mathrm{~m}$ \\
\hline Inertial Entry Velocity & 10 to $16 \mathrm{~km} / \mathrm{s}$ \\
\hline Inertial Entry Flight Path Angle & $-5^{\circ}$ to $-25^{\circ}$ \\
\hline
\end{tabular}

Continued development of the MMEEV models include:

- more sophisticated parametric configuration models, including payload accommodation

- higher fidelity impact dynamics model (e.g. finiteelement model)

- updated aerodynamics models based on ground (e.g. wind tunnel and ballistic range) testing as well as Computational Fluid Dynamics (CFD) analysis

- high fidelity TPS mass/thickness sizing models for additional candidate TPS materials (PICA and carbon phenolic are currently supported).

MMEEV performance studies will continue with the eventual integration of the MMEEV models into the "MultiMission Systems Analysis for Planetary Entry” (M-SAPE) Tool. This is a prototype EDL analysis tool, originally developed in support of ISPT aerocapture studies. MSAPE's capabilities are currently being expanded to include landing. The code will support mission studies to any celestial body with an atmosphere. The M-SAPE tool contains low-, mid-, and high-fidelity models, and the user can specify the level of analysis to be performed. Highfidelity validated thermal protection system response models and trajectory simulation tools are incorporated into the baseline tool.[17] Plans for the next two years of development include ground tests to validate the other tool modules; in particular, the impact foam characteristics under thermal loads, and the impact dynamics.

To improve the fidelity of the system analysis, a preliminary thermal soak model was developed at NASA-Ames. The objective was to understand the thermal environment of the returned sample canister after the vehicle undergoes the heat pulse and waits to be recovered. Samples from various comets, asteroids, and planets may have differing thermal requirements. This analysis will help determine if active thermal control is needed or if the MMEEV design needs to be changed for some applications. Another critical analysis recently completed is a micrometeoroid and orbital debris (MMOD) impact assessment from NASA-JSC. The probability of impact during some mission profiles may drive the need for an MMOD shield. This will significantly affect the vehicle system design.

Detailed studies show that to meet the stringent containment requirements for a Mars sample return mission, the MMEEV should possess particular design attributes. First, the vehicle aerodynamics must be very well understood. This means utilizing a shape with extensive analysis, testing, and flight experience. The vehicle aerodynamics must also be "self-righting." It needs to quickly stabilize itself in a heatshield-forward orientation. The release from the ERV, a micrometeoroid impact, or some other anomaly, could cause it to enter the atmosphere in another orientation. Second, the heat shield TPS needs to be robust enough to ensure a high level of reliability for both nominal and offnominal (such as MMOD impacts) environments. Third, the MMEEV has no parachute or other deployable drag device. Because the reliability of such a device is several orders of magnitude less than the level likely required, the capsule would still need to be designed to survive and safely contain the sample after an Earth impact in the event of a failure of the drag device.

The biggest challenge for any space vehicle, including the MMEEV, is to adequately prove the reliability of the components, subsystems, and the flight system as a whole. The current estimate to develop the EEV technology for MSR to TRL 6 is approximately $\$ 41$ million. This does not include a dedicated flight test. Many experts agree, a flight test is needed is needed to achieve the $10^{-6}$ probability of failure because the entry flight environment cannot be replicated in ground-based facilities. It is possible to achieve flight validation by using the MMEEV design concept, or the major components of the design, in sample return missions likely to fly prior to MSR. There would be little extra cost to NASA to fly the MMEEV components on a New Frontiers or Discovery mission. NASA Headquarters managers and the In-Space Propulsion Technology team are pursuing this approach. Currently there are no manifested missions that are planning to use an MSR EEV design.

\section{SySTEMS/MisSiON ANALYSIS}

Systems analysis is used during all phases of any propulsion hardware development. The systems analysis area serves two primary functions:

1) to help define the requirements for new technology development and the figures of merit to prioritize the return on investment, 
2) to develop new tools to easily and accurately determine the mission benefits of new propulsion technologies allowing a more rapid infusion of the propulsion products.

Systems analysis is critical prior to investing in technology development. In today's environment, advanced technology must maintain its relevance through mission pull. Systems analysis is used to identify the future mission needs for decadal missions and discovery mission DRMs. The mission studies identify technology gaps and are used to quantify mission benefits at the system level. This allows studies to guide the investments and define metrics for the technology advancements. Recent systems analysis efforts included quantitative assessment of higher specific impulse Hall thrusters,[2,3,18,119,20] higher thrust-to-power gridded-ion engines, and evaluation of monopropellant system anomalies to assess failure modes and potential mitigation options. In addition to informing program decisions, the mission design studies provide an opportunity to work with the science/user community.

The second focus of the systems analysis project area is the development and maintenance of tools for the mission and systems analyses. Improved and updated tools are critical for the potential mission users to quantify the benefits and understand implementation of new technologies. A common set of tools increases confidence in the benefit of ISPT products both for mission planners and for potential proposal reviewers. For example, low-thrust trajectory analyses are critical to the infusion of new electric propulsion technology. The ability to calculate the performance benefit of complex electric propulsion missions is intrinsic to the determination of propulsion system requirements. Improved mission design tools repeatedly demonstrated the ability to enable greater science with reduced risk and/or reduced transit times. Every effort is made to validate, verify, and make publicly available the In-Space Propulsion Technology program tools. Instructions to obtain the tools currently available are provided on the ISPT program website.[21]

\section{Conclusion and Future Plans}

The future focus areas for ISPT are propulsion systems for sample return missions. Activity in these technology development areas increases in 2012 and 2013. The direction focuses on: 1) Planetary Ascent Vehicles; 2) multimission technologies for Earth Entry Vehicles required for sample return missions; and 3) electric and chemical propulsion for Earth Return Vehicles, transfer stages, and low cost Discovery-class missions. These sample return missions are inherently propulsion intensive. Several of the earlier ISPT technology areas may be involved in a single sample return mission. The mission may use Electric Propulsion for transfer to, and possibly back from, the destination. Chemical propulsion may be utilized for the ascent and descent to the surface. Aeroshells may be used for Earth re-entry and an aerocapture maneuver used to capture at the destination. Future sample return missions of interest for NASA and the science community, and those that are yet to be conceived, continue to demand propulsion systems with increasing performance and lower cost. This paper addressed how the ISPT program is starting to develop propulsion technologies for NASA's future samplereturn missions.

\section{ACKNOWLEDGMENTS}

The results and findings presented here are based on work funded by the National Aeronautics and Space Administration (NASA), Science Mission Directorate (SMD). ISPT implements the program through task agreements with NASA centers, contracts with industry, and via grants with academic institutions. Implementing NASA centers include Ames Research Center (ARC), Glenn Research Center (GRC), Jet Propulsion Laboratory (JPL), Langley Research Center (LaRC), and the Marshall Space Flight Center (MSFC). There are also numerous industry partners in the development of the ISPT products. The authors acknowledge the technical achievements by the respective NASA and contractor teams and the contributions of the respective technology area project managers. In addition, many thanks to Linda Nero for her administrative, editorial, and clerical support of this paper, and to Dan Vento for his editorial reviews and improvements. 


\section{REFERENCES}

[1] "Vision and Voyages for Planetary Science in the Decade 2013-2022," The National Academies Press, URL: http://www.nap/edu, 2011

[2] Anderson, D. J. Pencil, E. Peterson, T., Dankanich, J., Munk, M., "In-Space Propulsion Technology Products for NASA's Future Science and Exploration Missions,” 2011 IEEE Aerospace conference, March 2011, Paper \#1114.

[3] Anderson, D. J., Dankanich, J., Hahne, D., Pencil, E. Peterson, T., Munk, M., "Sample Return Propulsion Technology Development under NASA's ISPT Project,” 2011 IEEE Aerospace conference, March 2011, Paper \#1115

[4 Anderson, D. J., Pencil, E., Vento, D., Dankanich, J., Munk, M., Hahne, D., "Propulsion Technology Development for Sample Return Missions under NASA's ISPT Program,” AIAA-2011-5766, 47 ${ }^{\text {th }}$ Joint Propulsion Conference, San Diego Ca, July 31-August 3, 2011.

[5] Anderson, D. J., Dankanich, J., Munk, M., Pencil, E., Liou, L., "The NASA In-Space Propulsion Technology Project's Current Products, and Future Directions,” 2010 IEEE Aerospace Conference, March 2010, Paper \#1078

[6]Kamhawi, H., "Overview of the High voltage Hall Accelerator Project," AIAA-2009-5282, 45th AIAA/ASME/SAE/ASEE Joint Propulsion Conference and Exhibit, Denver, CO, August 2009.

[7] Dankanich, J. Cardin, J., Dien, A., Netwall, C., Osborn, M., and Kamhawi, H., "Advanced Xenon Feed System (AXFS) Development and Hot-fire Testing," AIAA2009-4910, 45 ${ }^{\text {th }}$ Joint Propulsion Conference, Denver, CO, August 2-6, 2009.

[8] Kamhawi, H., et al., "High Voltage Hall Accelerator Project Overview," IEPC-2009-092, Proceedings of the 31st International Electric Propulsion Conference, Ann Arbor, MI, September 2009.

[9] Kamhawi, H., Haag, T., Pinero, L., Huang, W., Peterson, T., Manzella, D., Dankanich, J., Mathers, A., Hobson, D., "Overview of the Development of a Low-Cost High Voltage Hall Accelerator Propulsion System for NASA Science Missions," AIAA-2011-5520, 47th AIAA/ASME/SAE/ASEE Joint Propulsion Conference and Exhibit, San Diego, CA, August 2011.

[10] Mattingly, R., and May, L., "Mars Sample Return as a Campaign,” IEEEAC Paper \#1805, 2011 IEEE Aerospace Conference, Big Sky, MT, March 5-12, 2011.

[11] Mattingly, R. M., "Mars Sample Return MAV Study Guidelines,” JPL D-66683 Rev. B, May, 2011.
[12] Mungas, Greg, Fisher, David, Vozoff, Joanne, and Villa, Marco, "NOFBX ${ }^{\mathrm{TM}}$ Single Stage to Orbit Mars Ascent Vehicle,” IEEEAC Paper \#1809, 2012 IEEE Aerospace Conference, Big Sky, MT, March 3-10, 2012.

[13] Dankanich, John W., and Klein, Eric, "Mars Ascent Vehicle Development Status," IEEEAC Paper \#1471, 2012 IEEE Aerospace Conference, Big Sky, MT, March 3-10, 2012.

[14] Ross, Douglas, Russell, James, and Sutter, Brian, "Mars Ascent Vehicle (MAV): Designing for High Heritage and Low Risk,” IEEEAC Paper \#1190, 2012 IEEE Aerospace Conference, Big Sky, MT, March 3-10, 2012.

[15] Trinidad, Mark A., Zabrensky, Ed, and Sengupta, Anita, " Mars Ascent Vehicle System Studies and Baseline Conceptual Design,” IEEEAC Paper \#1744, 2012 IEEE Aerospace Conference, Big Sky, MT, March 3-10, 2012.

[16] Sengupta, Anita, Pauken, Mike, Kennett, Andrew, Trinidad, Mark A., and Zabrensky, Ed, "Systems Engineering and Technology Considerations of a Mars Ascent Vehicle,” IEEEAC Paper \#1511, 2012 IEEE Aerospace Conference, Big Sky, MT, March 3-10, 2012.

[17] Samareh, Jamshid A., Maddock, Robert W., and Winski, Richard G., "An Integrated Tool for System Analysis of Sample Return Vehicles,” IEEEAC Paper \#1169, 2012 IEEE Aerospace Conference, Big Sky, MT, March 3-10, 2012

[18] Dankanich, J. W., Kamhawi, H., and Mathers, A., "HIVHAC Maximum Operating Power Mission Impacts," IEPC-2009-213, 2009 International Electric Propulsion Conference, Ann Arbor, MI, September 20-24, 2009.

[19] Cupples, M., Coverstone, V., and Woo, B., "Applications of Solar Electric Propulsion to a Comet Surface Sample Return Mission,” AIAA-2004-3804, 40th AIAA/ASME/SAE/ASEE Joint Propulsion Conference and Exhibit, Fort Lauderdale, GL, July, 2004.

[20] Oh, D., "Evaluation of Solar Electric Propulsion Technologies for Discovery Class Missions," AIAA2005-4270, 41st AIAA/ASME/SAE/ASEE Joint Propulsion Conference \& Exhibit, Tucson, AZ, July, 2005.

[21] NASA ISPT Web site URL: http://spaceflightsystems.grc.nasa.gov/Advanced/Science Project/ISPT/LTTT/. 


\section{BIOGRAPHIES}

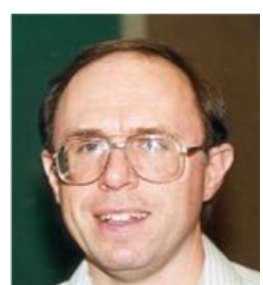

David Anderson is a program manager in the Science Project Office at the NASA (GRC). He is currently the Acting Program Manager for the In-Space Propulsion Technology (ISPT) program, and is the SBIR Spacecraft and Platform Subsystems Topic Manager. Formerly, he managed the advanced Radioisotope Power System (RPS) efforts at NASA GRC, was active with new business development and proposal development activities. He worked in GRC's Systems Management Office, where he was involved in project management oversight activities and led or was involved in several Center and NASA-wide program/project management process improvement teams or activities. He has a B.S. in Aerospace Engineering from the University of Cincinnati and an M.S. in Engineering Management from the Cleveland State University.

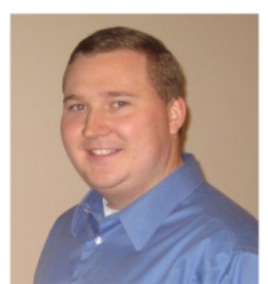

John Dankanich is a Gray Research contractor to the NASA Glenn Research Center. He is the electric propulsion lead systems engineer for the ISPT program. He also serves as a mission and systems analyst for the ISPT program and the Glenn Research Center. John has expertise in mission and systems analyses, electric propulsion systems, and trajectory optimization. He supported propulsion system development, Mars ascent vehicle design, lunar lander guidance simulations, planetary defense studies, and advanced propulsion design and testing. John has a B.S. in Physics and Aerospace Engineering and an M.S. in Aerospace Engineering from Purdue University.

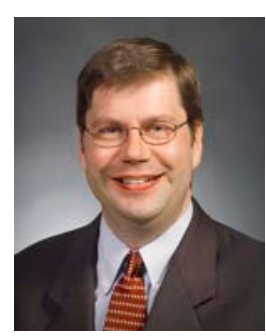

Eric Pencil is Propulsion Projects Area Manager for the In-Space Propulsion Technology Office at NASA Glenn Research Center. He is responsible for the management and execution of the electric propulsion development tasks for NASA Science missions. Previously he worked as a project/research engineer in the electric propulsion research group in which he worked on various electric propulsion technologies at varying stages of maturity from basic research to flight hardware.

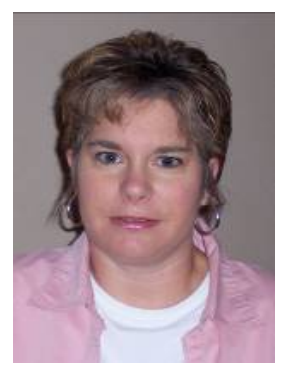

Michelle Munk has been a NASA employee for nearly 20 years, first at the Johnson Space Center, then at the Langley Research Center. She has been involved in Mars advanced mission studies for many years, both robotic and human, contributing interplanetary trajectory analysis and entry and descent analysis. She managed the delivery of International Space Station hardware, and was on the Mars Odyssey aerobraking operations team. In 2002, Ms. Munk accepted a detail assignment to become the Lead Engineer for Aerocapture Technology Development under In-Space Propulsion at Marshall Space Flight Center. She managed the technical work of ISP Aerocapture for nearly five years before becoming the Project Area Manager and returning to Langley in 2007. Ms. Munk is also involved in the Mars Science Laboratory Entry, Descent and Landing Instrumentation (MEDLI) project and contributes to other NASA projects developing entry system technologies. She has a BSAE from Virginia Tech and completed graduate coursework at the University of Houston.

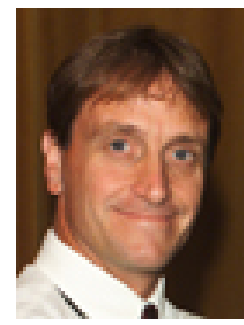

Lou Glaab is currently an assistant project manager in the Entry Vehicle Technology area. Mr Glaab has been working at NASA for over 25 years. His experience at NASA includes aircraft stability and control, crew-vehicle interface design, unmanned ariel vehicles, and aerosciences for the Constellation Program $(C x P)$. He has a B.S. in Aerospace Engineering from the University of Buffalo, NY, and an M.S. in Aeronautical Engineering from George Washington University.

Todd Peterson is a project manager in the Advanced

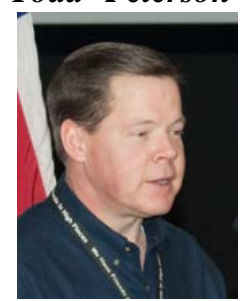
Capabilities Project Office at the NASA Glenn Research Center (GRC). With over 26 years of space flight project experience at NASA GRC, he has extensive propulsion, power and communication system project management experience in human and robotic space flight projects (Space Station, Shuttle/Mir, Deep Space-1, Earth Observer-1, Lunar Reconnaissance Orbiter) and development projects (electric propulsion, chemical propulsion, photovoltaic \& dynamic power systems, microgravity research). He has a B.S. in Mechanical Engineering from the University of Akron and an M.S. in Mechanical Engineering from Cleveland State University. 